\title{
Treatment with granulocyte colony-stimulating factor ameliorates chronic heart failure
}

\author{
Yiwen Li ${ }^{1}$, Genzou Takemura ${ }^{1}$, Hideshi Okada ${ }^{1}$, Shusaku Miyata ${ }^{1}$, Masayasu Esaki ${ }^{1}$, \\ Rumi Maruyama ${ }^{1}$, Hiromitsu Kanamori ${ }^{1}$, Longhu Li ${ }^{1}$, Atsushi Ogino ${ }^{1}$, Yu Misao ${ }^{1}$, \\ Ngin C Khai ${ }^{2}$, Atsushi Mikami ${ }^{2}$, Shinya Minatoguchi ${ }^{1}$, Takako Fujiwara ${ }^{3}$ \\ and Hisayoshi Fujiwara ${ }^{1}$
}

${ }^{1}$ Second Department of Internal Medicine, Gifu University School of Medicine, Gifu, Japan; ${ }^{2}$ Division of Gene Therapy and Cardiovascular Regeneration, Gifu University School of Medicine, Gifu, Japan and ${ }^{3}$ Department of Food Science, Kyoto Women's University, Kyoto, Japan

\begin{abstract}
Chronic heart failure remains a leading cause of mortality. Although granulocyte colony-stimulating factor (G-CSF) is reported to have a beneficial affect on postinfarction cardiac remodeling and dysfunction when administered before the onset of or at the acute stage of myocardial infarction (MI), its effect on established heart failure is unknown. We show here that subcutaneous administration of G-CSF greatly improves the function of murine hearts failing due to a large, healed MI. G-CSF changed the geometry of the infarct scar from elongated and thin to short and thick, induced hypertrophy among surviving cardiomyocytes, and reduced myocardial fibrosis. Expression of G-CSF receptor was confirmed in failing hearts and was upregulated by G-CSF treatment. G-CSF treatment also led to activation of signal transducer and activator of transcription-3 and induction of GATA-4 and various sarcomeric proteins such as myosin heavy chain, troponin I and desmin. Expression of metalloproteinase-2 and -9 was also increased in G-CSF-treated hearts, while that of tumor necrosis factor- $\alpha$, angiotensin II type 1 receptor (AT1) and transforming growth factor- $\beta 1$ was reduced. Although activation of Akt was noted in G-CSF-treated hearts, vessel density was unchanged, and apoptosis was too rare to exert a meaningful effect. No bone marrow-derived cardiomyocytes or vascular cells were detected in the failing hearts of green fluorescent protein chimeric mice. Finally, beneficial effects of G-CSF on cardiac function were found persisting long after discontinuing the treatment ( 2 weeks). Collectively, these findings suggest G-CSF administration could be an effective approach to treating chronic heart failure following a large MI. Laboratory Investigation (2006) 86, 32-44. doi:10.1038/labinvest.3700367; published online 21 November 2005
\end{abstract}

Keywords: chronic heart failure; cytokines; G-CSF; remodeling; signal transduction

Heart failure remains a leading cause of mortality in large part because of a lack of therapies targeted to the underlying biological processes within cardiomyocytes that lead to chronic dysfunction. ${ }^{1}$ Currently, heart transplantation is the only curative procedure for end-stage heart failure, but it is limited by donor heart availability. Occlusion of a diseased coronary artery in humans causes acute myocardial infarction (MI), survivors of which are at high risk for development of chronic heart failure. ${ }^{2}$ Rapid recanalization of the occluded coronary artery is presently the best clinical approach to the treatment of acute MI, which, if carried out in time,

Correspondence: Professor H Fujiwara, MD, PhD, Second Department of Internal Medicine, Gifu University School of Medicine, 1-1 Yanagido, Gifu 501-1194, Japan.

E-mail: gifuim-gif@umin.ac.jp

Received 19 July 2005; revised 28 September 2005; accepted 29 September 2005; published online 21 November 2005 enables salvage of the ischemic myocardial cells. Unfortunately, most patients miss the chance for coronary reperfusion therapy because, to be effective, it must be performed within a few hours after the onset of infarction. ${ }^{3}$ Indeed, patients with postinfarction heart failure account for nearly half of the candidates for cardiac transplantation. ${ }^{4}$ Consequently, development of an effective therapy with which to treat patients admitted to the hospital with symptoms of established heart failure is one of the most important issues in the field of cardiovascular medicine today.

The hematopoietic cytokine granulocyte colonystimulating factor (G-CSF) is a critical regulator of myeloid progenitor cell proliferation, differentiation and survival. ${ }^{5}$ G-CSF also causes a marked increase in the mobilization of hematopoietic stem cells into the peripheral blood circulation, ${ }^{6,7}$ and it has been proposed that G-CSF might induce the regeneration of cardiomyocytes and blood vessels in post-MI 
hearts through mobilization and subsequent transdifferentiation of such bone marrow stem cells. ${ }^{8}$ Although there is some experimental support for this idea, ${ }^{9}$ more recent reports would seem to rule out that possibility, irrespective of G-CSF's involvement. ${ }^{10-12}$ Nevertheless, it is widely accepted that G-CSF can improve cardiac function and reduce mortality following MI. ${ }^{8,13-16}$ For instance, we previously reported that postinfarction treatment with G-CSF accelerates the healing process after MI by augmenting macrophage accumulation in the infarcted area and upregulating expression of matrix metalloproteinase (MMP) family enzymes. ${ }^{15}$ And more recently, Harada et $a l^{16}$ reported that G-CSF protected cardiomyocytes and endothelial cells from apoptotic cell death via activation of the Janus kinase (Jak)/signal transducer and activator of transcription (Stat) pathway, although the significance of cardiomyocyte apoptosis in MI and heart failure is still controversial. ${ }^{17-19}$ Because all of these studies were carried out using models in which treatment with G-CSF was started before or within days after the onset of acute MI, it remains unknown whether late treatment with G-CSF would be effective against established heart failure during the chronic stage following an old MI, at time when acute inflammatory foci would have already disappeared and a fibrotic scar would be present.

The aim of the present study was to investigate the effects of G-CSF on established cases of chronic heart failure in a post-MI mouse model. Our findings suggest that administration of G-CSF could be an effective approach to the treatment of chronic heart failure following a large, healed MI.

\section{Materials and methods}

\section{Experimental Heart Failure}

The study was approved by our Institutional Animal Research Committee. MI was induced in 12-weekold male C57BL/ 6 mice by ligating the left coronary artery as previously described. ${ }^{20}$ The suture was passed but not tied in the sham-operated mice.

\section{Treatment with G-CSF}

\section{Protocol-1}

MI was created in 46 mice and sham operation was performed in 14 mice. At 12 weeks after the operation, the surviving mice were 24 (survival rate, $52 \%$ ) in MI group while all mice survived in shamoperated group. The MI-bearing mice were randomly assigned to two groups, resulting in similar echocardiography-based cardiac function between the groups. Recombinant human G-CSF (Chugai Pharmaceutical Co.) was administered subcutaneously at a dosage of $10 \mu \mathrm{g} / \mathrm{kg} /$ day to 14 MI-bearing mice beginning when the animals reached 24 weeks of age (12 weeks post-MI). The injections were performed on the first 5 days of each week, and were continued for 4 weeks until the animals were 28 weeks of age (16 weeks post-MI). In the untreated control group, the same volume of solvent (distilled water, approximately $150 \mu \mathrm{l}$ per animal) was given to 10 MI-bearing mice over the same period. A total of 14 sham-operated mice (survival rate, $100 \%$ at 12 weeks after operation) were assigned to two groups in the similar manner based on echocardiography and they were similarly treated with G-CSF $(n=6)$ or solvent $(n=8)$. The dosage of G-CSF in the present study seems smaller and the interval longer relative to those of previous studies ${ }^{8,13,14,16}$ - for example, G-CSF at the dose of $100 \mu \mathrm{g} / \mathrm{kg} /$ day was administered for 5 days by Harada et al. ${ }^{16}$ We set it up at closer dosage to that clinically used, and instead, longer interval based on anticipation that different from the case of acute infarct with highly dynamic tissue, a long time might be necessary for a reagent to affect failing hearts with stout infarct lesion.

One day before the animals were killed, Evans blue dye (1\% v/v, Sigma-Aldrich) was intraperitoneally injected into three randomly chosen MIbearing mice in each group to detect cardiomyocytes with increased membrane permeability. ${ }^{21}$ At the end of experiments, cardiac geometry and function were examined using echocardiography and cardiac catheterization, and a necropsy was performed for histological and biochemical analyses.

\section{Protocol-2}

Too long-term treatment with G-CSF may be impossible in actual clinical situations because of unfavorable side effects of G-CSF. In the second protocol, therefore, we investigated whether the effects of G-CSF persist, even after treatment is stopped. MI was created in 36 mice, of which 20 mice were alive at 8 weeks after operation (survival rate, $56 \%$ ). They were assigned into two groups after echocardiographic examination, and administered G-CSF or solvent ( $n=10$ each) for 2 weeks using the same method described in Protocol-1. At 2 weeks after stopping treatment (12 weeks post-MI), cardiac function was examined by echocardiography and cardiac catheterization.

\section{Protocol-3}

In another set of experiments, we examined the possibility that G-CSF induces bone marrow cellderived myocardial regeneration. Bone marrow cells were harvested from the femurs and tibias of donor green fluorescent protein (GFP)-transgenic mice with a C57BL/6 background ${ }^{22}$ (a kind gift from Drs Yasushi Adachi and Susumu Ikehara, Kansai Medical School, Moriguchi, Japan). The harvested cells were then transplanted directly into the bone marrow space of femurs of 8-week-old male C57BL/6 mice $(n=20)$ that had received whole body irradiation as described previously. ${ }^{23}$ After 
4 weeks, MI was induced in the 15 surviving chimeric mice. To nine of the surviving mice 12 weeks post-MI, G-CSF $(n=5)$ or solvent $(n=4)$ was administered for 4 weeks using the same method as described in Protocol-1.

\section{Blood Sampling}

Blood was drawn from the tail vein before treatment and from the inferior vena cava at the time animals were killed and used for hemocounts. Blood obtained at the time animals were killed was used also for measurement of plasma concentration of human G-CSF, which was performed using a chemiluminescent immunoassay kit (Kamiya Biomedical Co.).

\section{Physiological Studies}

Physiological studies were carried out as previously described. ${ }^{20}$ Echocardiograms were recorded with an echocardiographic system (Aloka, Japan) equipped with a 7.5-MHz imaging transducer at 12 and 16 weeks after surgery. Following the second echocardiogram, the right carotid artery was cannulated with a micromanometer-tipped catheter (SPR 407, Millar Instruments) and advanced into the aorta and then into the left ventricle to record pressure and maximal and minimal $\mathrm{d} P / \mathrm{d} t$.

\section{Histological Studies}

After the physiological measurements were completed in Protocol-1, the hearts were removed and the ventricles were cut into two transverse slices through the middle of the infarct. The apical specimens were quickly frozen in liquid nitrogen or used to prepare cryosections. The basal specimens were immersion fixed in $10 \%$ buffered formalin and embedded in paraffin, after which $4 \mu \mathrm{m}$-thick sections were stained with hematoxylineosin (H\&E), Masson's trichrome or Sirius red. Quantitative assessments, including MI size, cell population, cardiomyocyte size and fibrotic area, were performed using a LUZEX F multipurpose color image processor (Nireco, Tokyo, Japan). The sizes of the MI area and the fibrotic area in the noninfarcted region were measured by searching the entire ventricular area. Cardiomyocyte size (expressed as the transverse diameter of the cardiomyocyte cut at the level of the nucleus) and cell populations were assessed in 20 randomly chosen high-power fields in each section.

The hearts from mice in Protocol-2 were used exclusively to prepare cryosections. The ventricles were cut into three transverse blocks. At least 20 cryosections ( $8 \mu \mathrm{m}$ thick) were cut from each block; thus, more than 60 cryosections were made from each heart.

\section{Western Blotting}

Proteins $(100 \mu \mathrm{g})$ extracted from the hearts in Protocol-1 were subjected to 14\% PAGE and then transferred onto PVDF membranes. The membranes were then probed using a primary antibody against G-CSF receptor (G-CSFR, Santa Cruz), phospho-Akt (Cell Signaling), phospho-Stat3 (Cell Signaling), phospho-extracellular signal-regulated kinase (phospho-ERK, Cell Signaling), GATA-4 (Santa Cruz), myosin heavy chain (MHC, Santa Cruz), troponin I (Santa Cruz), desmin (Sigma), MMP-2 (Daiichi Fine Chemical Co.), MMP-9 (Santa Cruz), tissue inhibitor of MMP-1 (TIMP1, Santa Cruz), TIMP2 (Santa Cruz), angiotensin II type 1 receptor (AT1, Santa Cruz), transforming growth factor (TGF$\beta 1$, Promega), or Ki-67 (Santa Cruz). The blots were visualized by means of chemiluminescence (ELC, Amersham), and the signals were quantified by densitometry. $\alpha$-Tubulin (analyzed using antibody from Sigma-Aldrich) served as the loading control.

\section{Enzyme-Linked Immunosorbant Assay}

Myocardial tumor necrosis factor (TNF)- $\alpha$ content was quantified using an enzyme-linked immunosorbant assay (ELISA) kit (Quantikine ${ }^{\circledR} \mathrm{M}, \quad \mathrm{R} \& \mathrm{D}$ System) according to the supplier's instructions.

\section{Immunohistochemistry}

The sections were incubated with a primary antibody against GFP (Molecular Probes), CD45 (Pharmingen), MHC, Flk-1, Ki-67, G-CSFR (antibodies against MHC through G-CSFR, from Santa Cruz), MMP-2 (Daiichi), MMP-9 (Santa Cruz), AT1 (Santa Cruz), or TGF- $\beta$ (Promega). The deparaffinized sections were immunostained using an ABC kit (Vector) with DAB as the chromogen. For the immunofluorescent staining of cryosections, Alexa Fluor 568 and 488 (Molecular Probes) were the secondary antibodies. Nuclei were counterstained with hematoxylin or Hoechst 33342. In situ nick end-labeling (TUNEL) assays were carried out to detect apoptotic cells within deparaffinized sections using an ApopTag kit (Intergene) with FITC-labeling (Intergene) according to the manufacturer's instructions. Mouse mammary tissue served as a positive control. For double-label immunohistochemistry, sections were stained first using TUNEL (FITClabeling), then using a second primary antibody against MHC followed by Alexa Fluor 568. The sections were observed under either a light microscope or confocal laser scanning microscope (LSM510, Zeiss). As the negative controls, sections were incubated with the isotype immunoglobulins instead of the primary antibodies. For all sections, the staining was interpreted by two observers blinded to the specimen's group. The percentage of 
immunopositive cells present was calculated in 20 randomly chosen high-power fields in each section.

\section{Statistical Analysis}

Values are shown as mean \pm s.e.m. The significance of differences between groups was evaluated using $t$ tests or one-way ANOVA followed by the NewmanKeul's multiple comparison test. Values of $P<0.05$ were considered significant.

\section{Results}

\section{Effect of G-CSF on Chronic Heart Failure}

Mice bearing 12-week-old MIs were subcutaneously injected with recombinant human G-CSF $(n=14)$ or vehicle $(n=10)$ for 4 weeks (Protocol 1 in the Materials and methods section). After 4 weeks (16 weeks after surgery), all mice of each group were still alive. The granulocyte count in animals treated for 4 weeks with G-CSF reached $4354 \pm 673 / \mu$ l, which was significantly higher than the counts obtained from untreated controls $(819 \pm 278 / \mu \mathrm{l}$, $P<0.05)$ and the baseline counts obtained from the groups before induction of MI $(427 \pm 59 / \mu \mathrm{l}, P<0.05)$. There was no significant difference in the red blood cell or platelet counts between the groups. The plasma human G-CSF level in the G-CSFtreated mice was significantly greater than that in the untreated mice $(2.34 \pm 0.626$ vs $0 \pm 0 \mathrm{ng} / \mathrm{ml}$, $P<0.05)$. Echocardiograms revealed the mice with 12-week-old MI to have significant left ventricular (LV) dilatation and dysfunction, as compared to the sham-operated mice (Figure 1a and b). They also revealed an aggravation of the LV enlargement and ejection fraction reduction during the following 4 weeks in the untreated group. In contrast, they were improved in the G-CSF-treated group (Figure 1a and b). Cardiac catheterization also showed significant improvement of cardiac function-that is, greater LV developed pressure (LVDP), greater maximal and minimal $\mathrm{d} P / \mathrm{d} t$, and lower $\mathrm{LV}$ end-diastolic pressure (LVEDP)-in the G-CSF-treated group (Figure 1c-f). G-CSF did not affect cardiac function in shamoperated mice (Figure 1).

At necropsy, all of the hearts with 16-week-old MIs showed dilated LV cavities, although the dilatation was less marked in hearts treated with G-CSF (Figure 2a). On the other hand, the heart weights and heart-to-body weight ratios were not different in the untreated and G-CSF-treated groups (Figure 3a), nor was the MI area $\left(5.81 \pm 0.96 \mathrm{~mm}^{2}\right.$ in control vs $4.64 \pm 0.47 \mathrm{~mm}^{2}$ in G-CSF, $P=\mathrm{NS})$, the LV area $\left(19.21 \pm 1.51 \mathrm{~mm}^{2}\right.$ in control vs $20.71 \pm 1.06 \mathrm{~mm}^{2}$ in the G-CSF group, $P=\mathrm{NS}$ ) or the $\overline{\mathrm{MI}}$ area relative to the total $\mathrm{LV}$ area (Figure 3b). However, the wall thickness of MI region was found significantly greater in the G-CSF-treated hearts $(263 \pm 13.2 \mu \mathrm{m})$ than in the
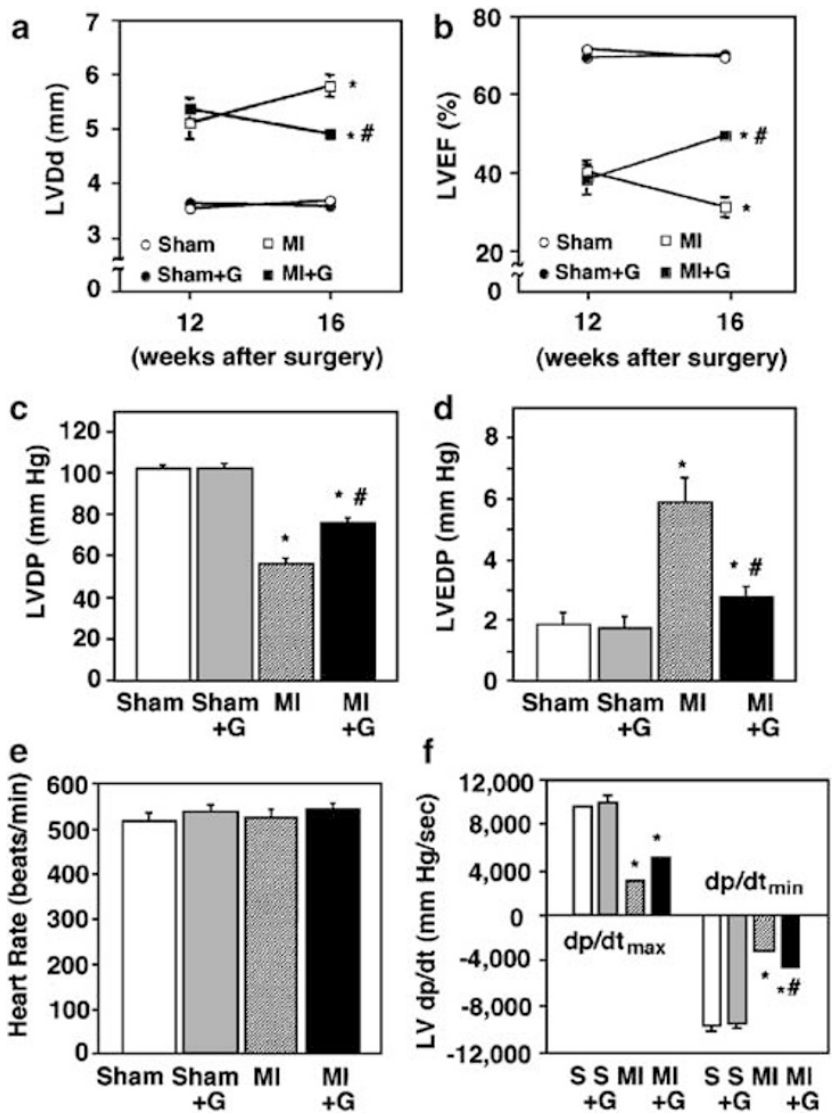

Figure 1 Effects of G-CSF on cardiac geometry and function: $S$ untreated sham-operated mice; Sham $+\mathrm{G}$ and $\mathrm{S}+\mathrm{G}$, G-CSFtreated sham-operated mice; MI, untreated mice with 16-weekold MI; MI + G, G-CSF-treated mice with 16-week-old MI; LVDd, left ventricular end-diastolic diameter, respectively; LVEF, left ventricular ejection fraction; LVDP and LVEDP, left ventricular developed and end-diastolic pressure, respectively. ${ }^{*} P<0.05$ vs Sham; ${ }^{\#} P<0.05$ vs MI.

untreated hearts $(151 \pm 20.0 \mu \mathrm{m}, P<0.05)$ (Figures 2a and 3c). Histologically, the sizes of the surviving cardiomyocytes were increased in all MI-bearing mice due to compensatory hypertrophy, but they were significantly larger in the G-CSF group than in the untreated control group (Figure 3d). There was also significantly more interstitial fibrosis in the noninfarcted area of untreated hearts than G-CSFtreated hearts (Figures $2 \mathrm{~b}$ and $3 \mathrm{e}$ ). The region of the 16-week-old infarct showed substantial fibrosis in all groups, but the intensity of Sirius red staining appeared somewhat weaker in the G-CSF-treated hearts (Figure 2c). Population of the Flk-1-positive vessels in either infarcted or noninfarcted area was similar between the untreated and G-CSF-treated hearts (Figure 3f). There were few CD45-positive leukocytes in infarcted areas, and their populations were similar between the groups (Figure 3g). Pulmonary congestion was readily apparent in the untreated group but was less so in G-CSF-treated animals (Figure 2d), and lung-to-body weight ratio was significantly smaller in the G-CSF group $(6.6 \pm 0.3 \mathrm{mg} / \mathrm{g}$ in control vs $5.9 \pm 0.3 \mathrm{mg} / \mathrm{g}$ in G- 
a

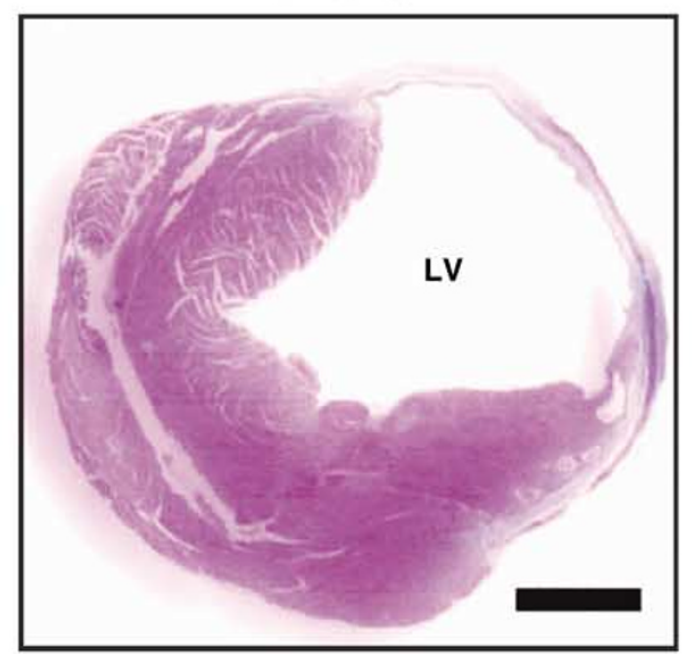

b

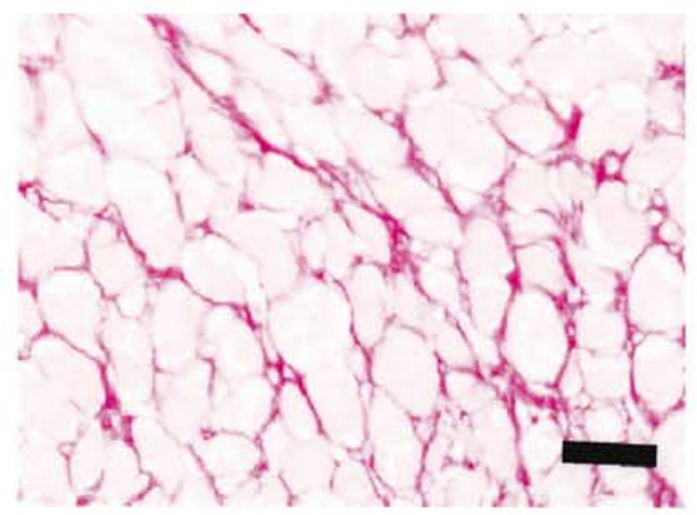

C

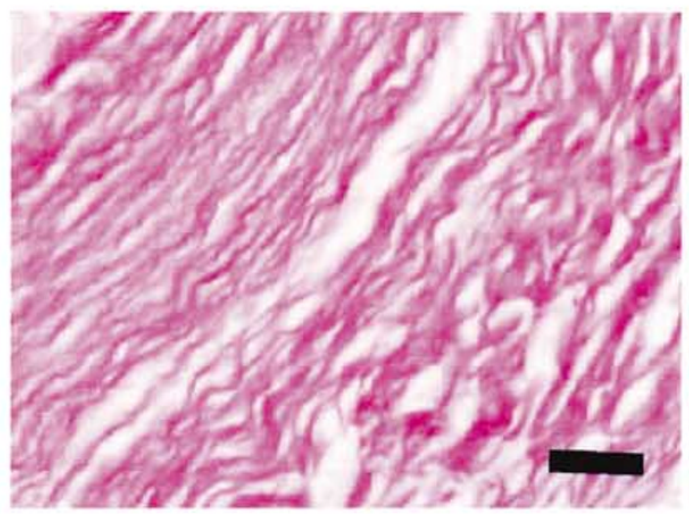

d

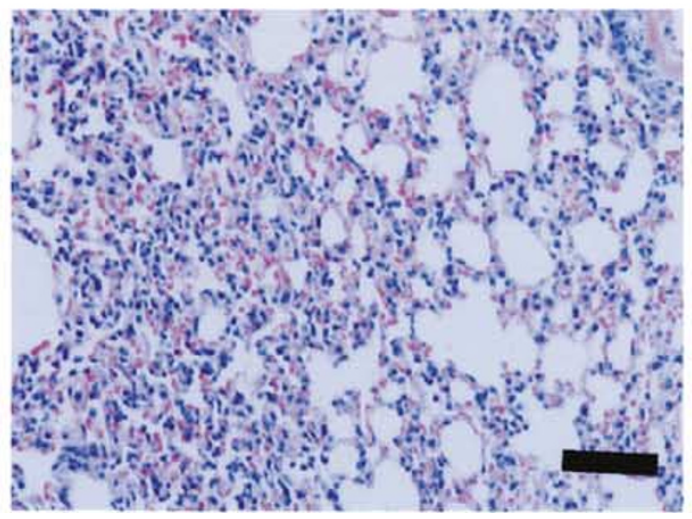

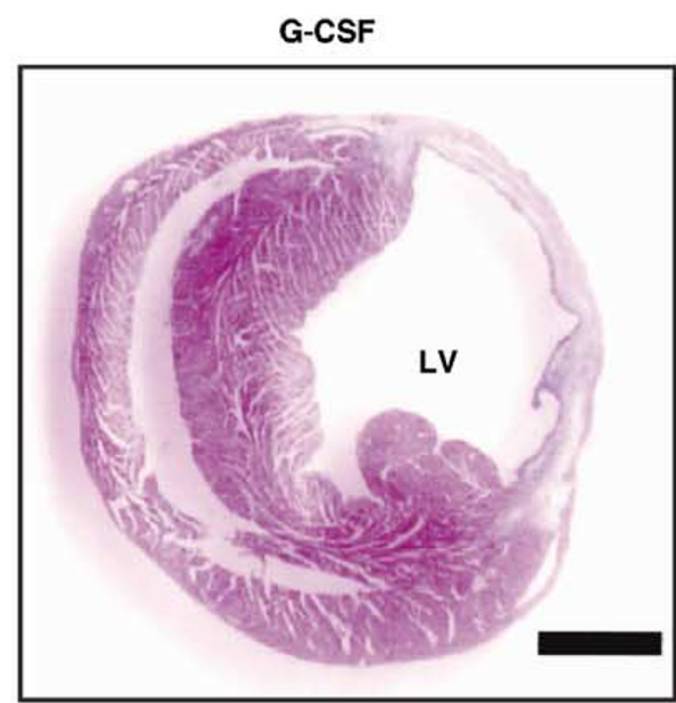
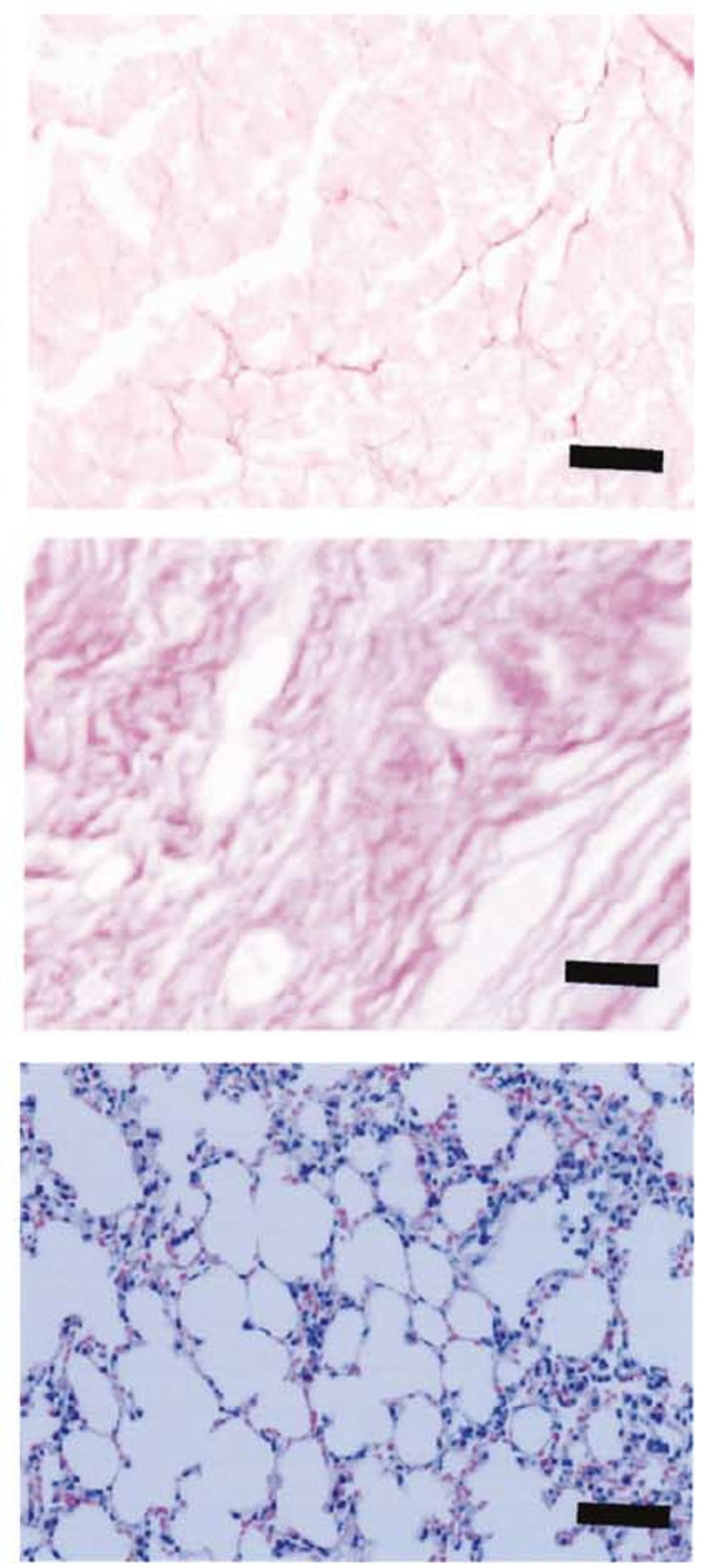

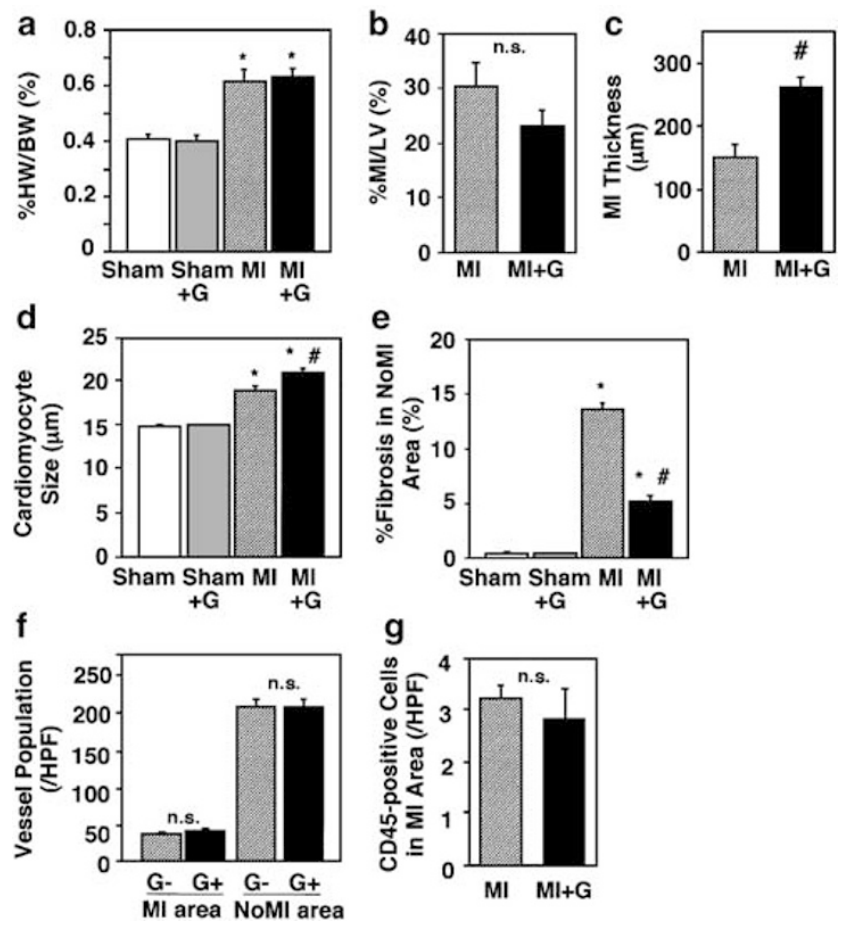

Figure 3 Morphometric data from murine hearts with 16-weekold MIs: Sham, untreated sham-operated mice; Sham + G, G-CSFtreated sham-operated mice; MI, untreated mice with 16-week-old MI; MI + G, G-CSF-treated mice with 16-week-old MI; HPF, highpower field. (a) Heart-to-body weight ratios. (b) Percent MI area relative to the total LV area. (c) Wall thickness of MI region. (d) Size of cardiomyocytes in noninfarcted areas. (e) Percent fibrosis in noninfarcted areas. (f) Number of vessels in infarcted areas. (g) Number of CD45-positive cells in infarcted areas. ${ }^{*} P<0.05$ vs Sham; ${ }^{\#} P<0.05$ vs MI.

CSF, $P<0.05)$. No adverse reactions to G-CSF, including splenic rupture, splenomegaly, thromboembolism, interstitial pneumonia, and atherosclerosis, were detected.

We then tested whether the effects of G-CSF would persist after stopping the treatment (Protocol-2 in the Materials and methods section). Mice with 8-week-old MIs were treated with G-CSF for 2 weeks, after which treatment was stopped for 2 weeks prior to examination as described above (12-week-old MIs). After 4 weeks (12 weeks after surgery), all mice of each group were surviving. Notably, even after 2 weeks without treatment, we found significantly better cardiac function in the G-CSF-treated group than the untreated group (Table 1).

\section{Molecular Signaling and Expression in Hearts Treated with G-CSF}

Western blot analysis showed that, as compared to expression in sham-operated hearts, myocardial
Table 1 Echocardiographic and cardiac catheterization data in MI-bearing mice recorded before and after 2 weeks discontinuation of the treatment with G-CSF or solvent followed by 2 weeks treatment

\begin{tabular}{|c|c|c|c|c|}
\hline \multirow{2}{*}{$\begin{array}{l}G-C S F \\
\mathrm{n}\end{array}$} & \multicolumn{2}{|c|}{ Pre } & \multicolumn{2}{|c|}{ Post } \\
\hline & $\begin{array}{c}(-) \\
10\end{array}$ & $\begin{array}{c}(+) \\
10\end{array}$ & $\begin{array}{c}(-) \\
10\end{array}$ & $\begin{array}{c}(+) \\
10\end{array}$ \\
\hline LVDd (mm) & $5.6 \pm 0.07$ & $5.7 \pm 0.07$ & $5.8 \pm 0.13$ & $5.3 \pm 0.12^{*}$ \\
\hline $\mathrm{EF}(\%)$ & $41 \pm 1.2$ & $39 \pm 1.6$ & $41 \pm 1.5$ & $50 \pm 1.1^{*}$ \\
\hline $\begin{array}{l}\text { Heart rate } \\
\text { (beats/min) }\end{array}$ & $510 \pm 19$ & $516 \pm 18$ & $531 \pm 18$ & $541 \pm 19^{*}$ \\
\hline LVDP (mmHg) & ND & ND & $73 \pm 2.4$ & $83 \pm 2.7^{*}$ \\
\hline LVEDP (mmHg) & ND & ND & $10 \pm 0.7$ & $4 \pm 0.7^{*}$ \\
\hline$+\mathrm{d} P / \mathrm{d} t(\mathrm{mmHg} / \mathrm{s})$ & ND & ND & $3690 \pm 230$ & $5660 \pm 398 *$ \\
\hline$-\mathrm{d} P / \mathrm{d} t(\mathrm{mmHg} / \mathrm{s})$ & ND & ND & $-3245 \pm 225$ & $-4958 \pm 408^{*}$ \\
\hline
\end{tabular}

See text for abbreviations.

${ }^{*} P<0.05$ compared with the untreated mice with MI.

expression of G-CSFR was significantly upregulated in hearts with 16-week-old MIs, whether they were treated with G-CSF or not (Figure 4a and b). Somewhat unexpectedly, the expression was actually stronger in the failing hearts treated with G-CSF than in the untreated hearts; moreover, a significant increase in G-CSFR expression was observed in the sham-operated hearts when G-CSF was administered. Confocal microscopy revealed that G-CSFR was expressed on surviving cardiomyocytes (MHCpositive) and interstitial cells within the scar tissue (Figure 4c). Taken together, these findings may indicate that G-CSFR is expressed in the failing myocardium and suggest that its expression may be regulated by a positive feedback mechanism dependent upon stimulation by G-CSF itself (autoinduction).

The binding of G-CSF to its receptor evokes signal transduction through activation of Jak/Stat; Akt kinase, which has been identified as a downstream target of phosphatidylinositol-3'-kinase (PI3K); and mitogen-activated protein kinase (MAPK)/ERK. ${ }^{6,16,24}$ Western blot analysis revealed that phospho-Stat3 and phospho-Akt, but not phospho-ERK, were upregulated in G-CSF-treated hearts, as compared to the untreated hearts (Figure 4a and d).

Our finding that G-CSF treatment caused cardiomyocyte hypertrophy with reduced degenerative changes prompted us to examine myocardial expression of GATA-4, a key transcriptional factor regulating expression of sarcomeric proteins in the heart. ${ }^{25,26}$ Myocardial expression of GATA-4 was downregulated in the failing hearts 16 weeks postMI, but that expression was restored by G-CSF treatment (Figure 5a and b). Moreover, the levels of

Figure 2 Photomicrographs of hearts (a-c) and lungs (d) from mice with 16-week-old MIs treated with vehicle (untreated, left panels) or G-CSF (right panels). (a) Transverse sections of hearts. (b) Highly magnified noninfarcted area stained with Sirius red. (c) Highly magnified infarcted area stained with Sirius red. (d) Lungs stained with H\&E. Bars in panel a, $1 \mathrm{~mm}$. Bars in panels b-d, $50 \mu \mathrm{m}$. 
38
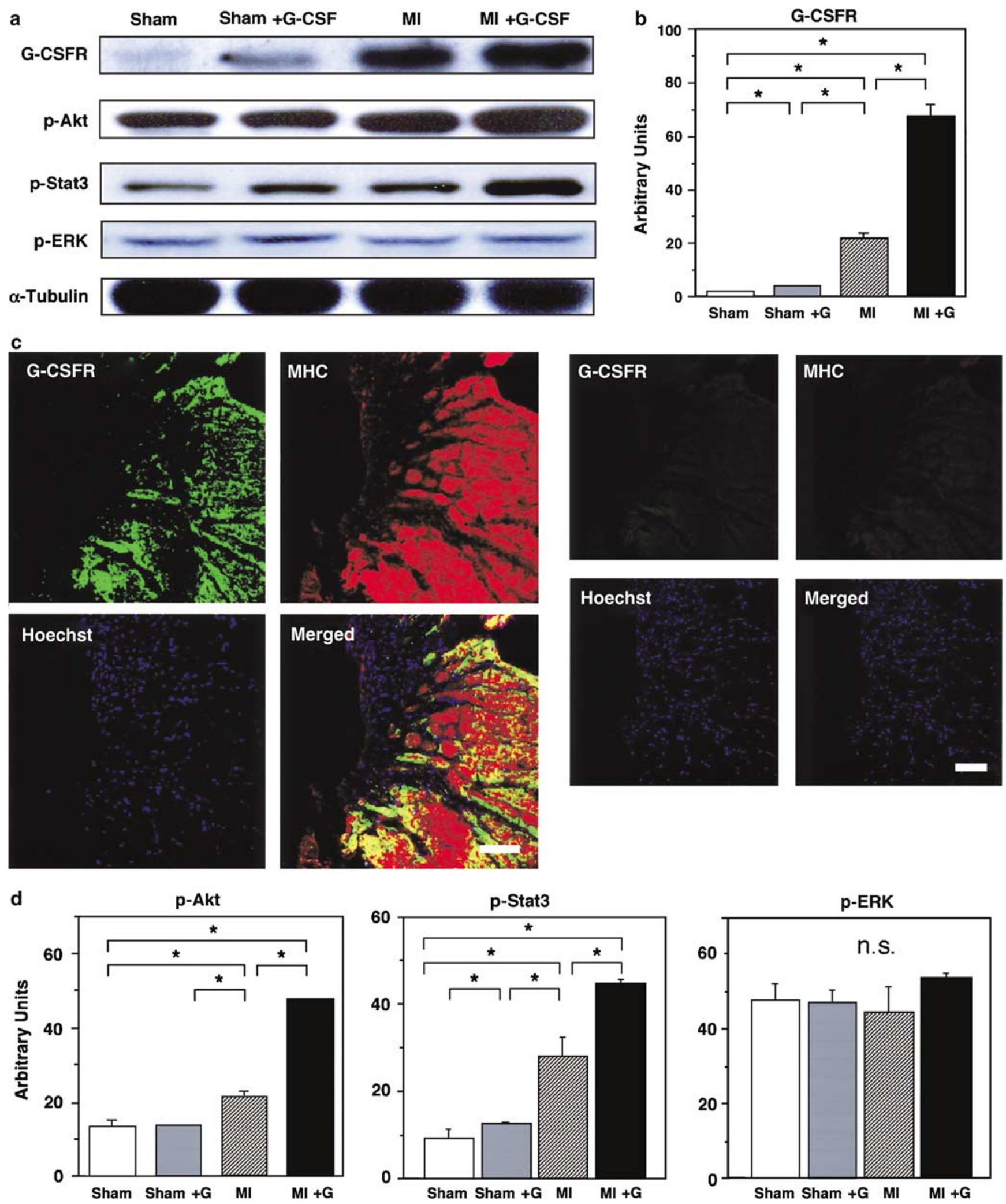

Figure 4 Expression of G-CSFR and activation of downstream signaling. (a) Western blot showing myocardial expression of G-CSFR, phospho-Akt, phospho-Stat5 and phospho-ERK. (b) Expression of G-CSFR quantified by densitometry. (c) Immunohistochemical analysis revealing the distributions of C-GSFR and MHC: G-CSFR, green; MHC, red; nuclei stained with Hoechst, blue; areas where GCSR and MHC overlap, yellow. Right panels show the serial section incubated with the isotype negative controls, showing neither green nor red fluorescence. Bars, $20 \mu \mathrm{m}$. (d) Expression of phospho-Akt, phospho-Stat5 and phospho-ERK quantified by densitometry. ${ }^{*} P<0.05$. 
several sarcomeric proteins (MHC, desmin and troponin I) were consistently higher in G-CSFtreated than untreated hearts (Figure $5 a$ and $b$ ).

We detected less fibrosis in the G-CSF-treated hearts than the control hearts, which is consistent with an earlier report that G-CSF induces MMP-2 (gelatinase A/type IV collagenase) and MMP-9 (gelatinase B). ${ }^{27}$ Indeed, our Western blot analysis showed that both MMP-2 and -9 were significantly overexpressed in G-CSF-treated hearts, as compared with untreated control hearts (Figure 6a and b). By contrast, levels of TIMP1 and TIMP2 were too slight to be affected by the G-CSF treatment (Figure 6a). $\mathrm{TNF}-\alpha$, which is elevated in patients with heart failure, is not only a cytotoxic cytokine that directly depresses cardiac function, ${ }^{28}$ but also upregulates AT1, thereby promoting angiotensin II-mediated organ fibrosis ${ }^{29}$ in part through production of the potently fibrogenic cytokine TGF- $\beta 1 .^{30}$ We noted here that G-CSF treatment significantly reduced expression of TNF- $\alpha$, AT1 and TGF- $\beta 1$ in hearts with 16-week-old MIs (Figure 6a and b), which, overall, would be expected to contribute to the reduction in fibrosis seen in G-CSF-treated hearts.
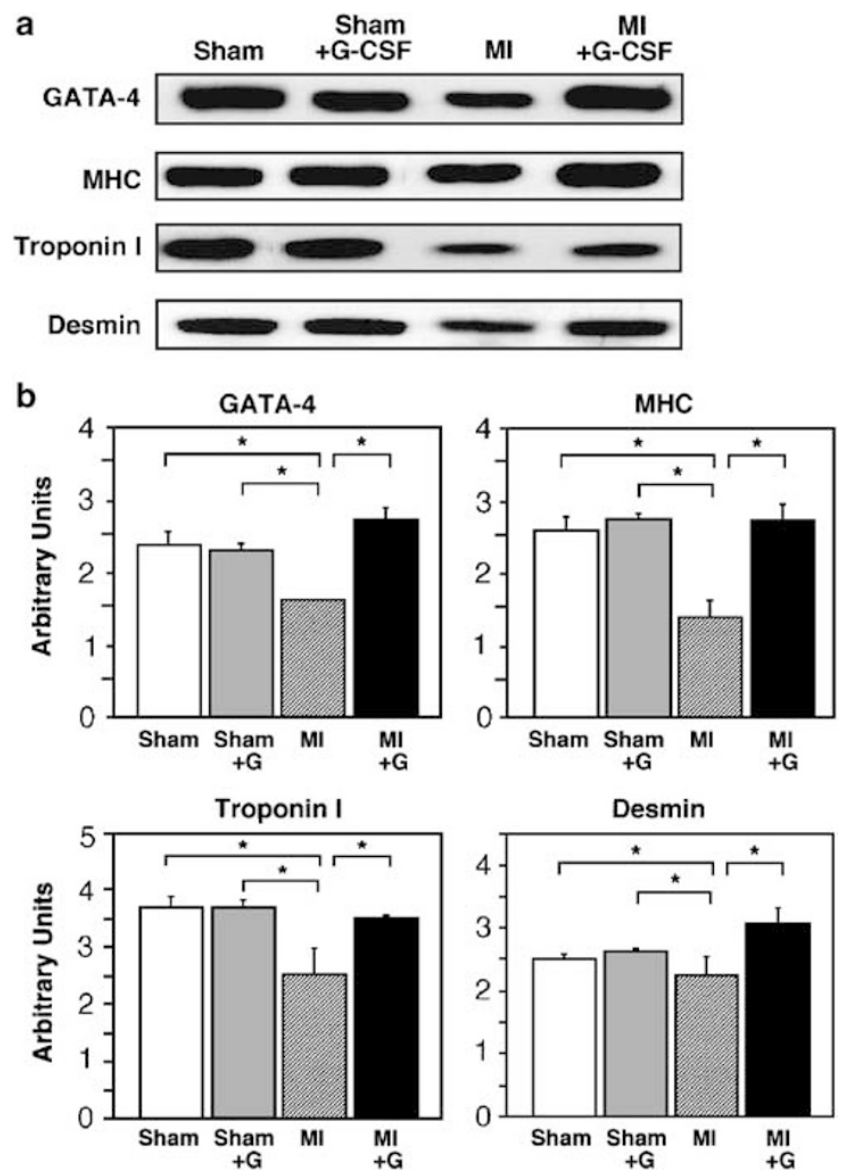

Figure 5 Eexpression of sarcomere-related proteins. (a) Western blot showing myocardial expression of GATA-4, MHC, troponin I and desmin. (b) Their quantification by densitometry. ${ }^{*} P<0.05$.
Immunohistochemistry revealed that MMP-2 was localized on fibroblasts, MMP-9 on fibroblasts and cardiomyoctes, AT1 not only on noncardiomyocytes such as endothelial cells, vascular smooth muscle cells, and fibroblasts but also on cardiomyocytes, and TGF- $\beta$ on noncardiomyocytes (endothelial cells, vascular smooth muscle cells, and fibroblasts) (Figure 6c). The intensity of immunostaining of MMP-2 and -9 was greater while that of AT1 and TGF- $\beta$ was weaker in the G-CSF-treated hearts, confirming the findings of Western blotting. These suggest that G-CSF affects, through downstream effectors of G-CSF receptor, not only cardiomyocytes but also noncardiomyocytes such as cardiac fibroblasts in failing hearts.

\section{Role for Myocardial Regeneration and Apoptosis}

We also used GFP chimeric mice to check for possible acceleration of myocardial regeneration by G-CSF (Protocol-3 in the Materials and methods section). In these mice, more than $85 \%$ of the bone marrow cells were found to be GFP-positive at necropsy. Within the infarcted areas of both untreated and G-CSF-treated hearts, a small proportion of GFP-positive cells that were round or fibroblastlike (spindle shaped) were observed (Figure 7a), and the incidence of GFP-positive cells did not appear to differ between G-CSF and untreated hearts $(0.38 \pm 0.16 \%$ in control vs $0.44 \pm 0.18 \%$ in G-CSF, $P=\mathrm{NS}$ ). In addition, double immunofluorescence showed that there were no GFP-positive cardiomyocytes (Figure 7b), endothelial cells or vascular smooth muscle cells in either group. We did occasionally identify cells that were positive for both GFP and CD45, however (Figure 7c). Each section incubated with the isotype negative control showed no fluorescence. No cardiomyocytes immunohistochemically positive for Ki-67 were observed (data not shown).

G-CSF was previously reported to protect cardiomyocytes from apoptotic cell death when administered during the acute stage of MI. ${ }^{13,16}$ We rarely detected apoptotic (TUNEL-positive) cardiomyocytes or noncardiomyocytes (including vascular cells) 16 weeks post-MI (Figure $7 \mathrm{~d}$ ), and the incidences of TUNEL-positive cells were unaffected by G-CSF treatment (Figure 7e). Moreover, electron microscopic examination revealed no apoptotic ultrastructure in cardiomyocytes in any group, and we never observed Evans blue-positive cells (data not shown), which is indicative of an absence of dying cells. ${ }^{21}$

\section{Discussion}

In the present study, we examined the effect of GCSF administration on established cases of chronic heart failure in a post-MI mouse model. We showed that G-CSF treatment post-MI induced hypertrophy 

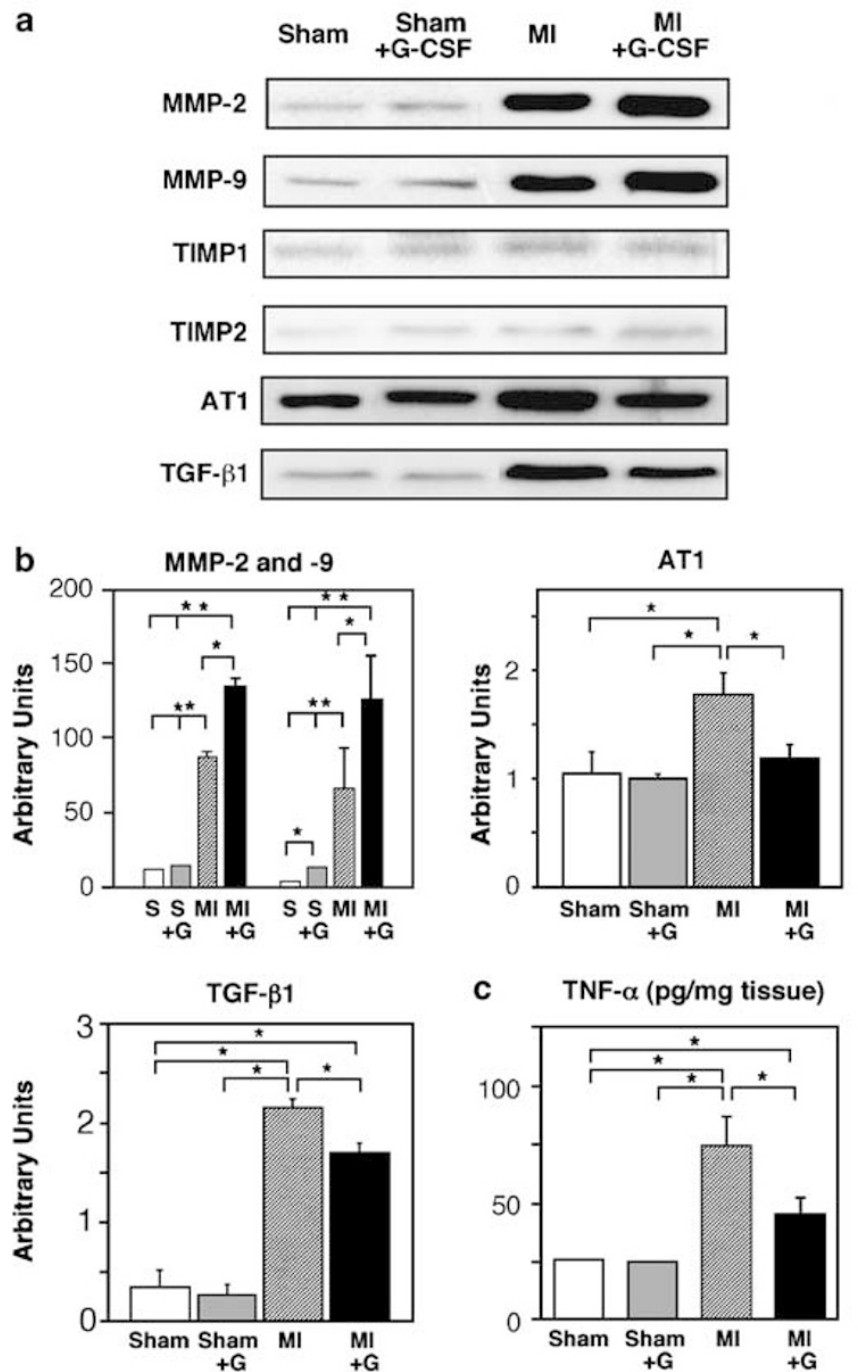

c

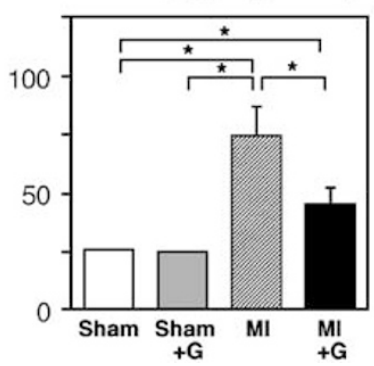

d
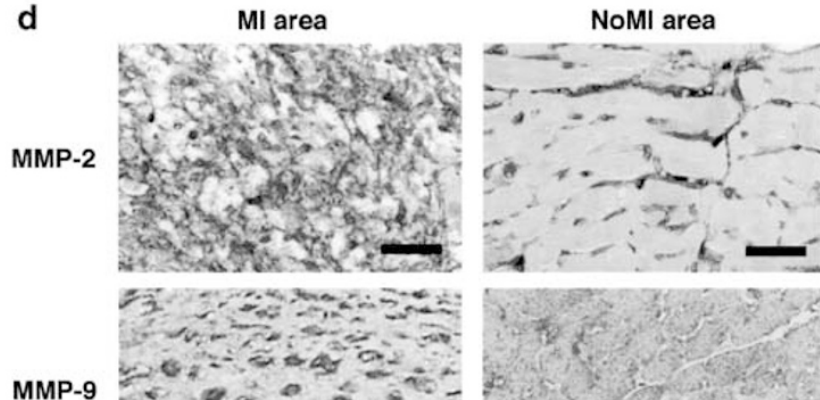

MMP-9

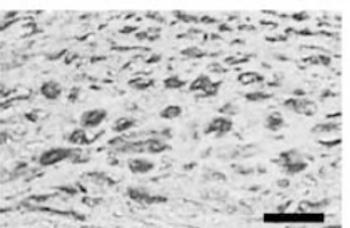

A1
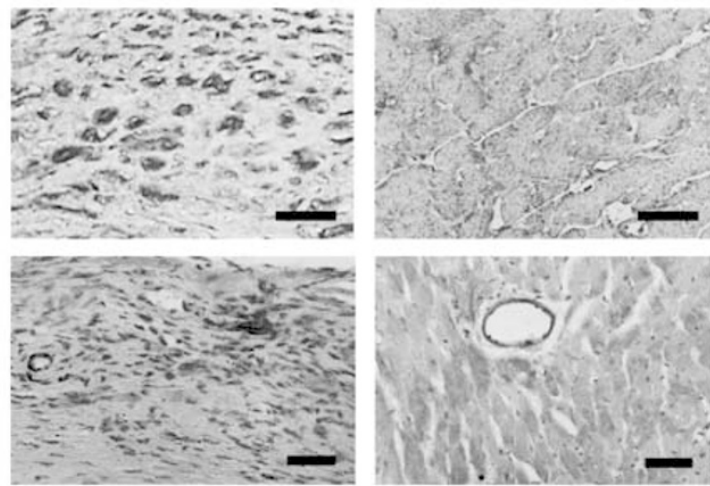

TGF- $\beta$
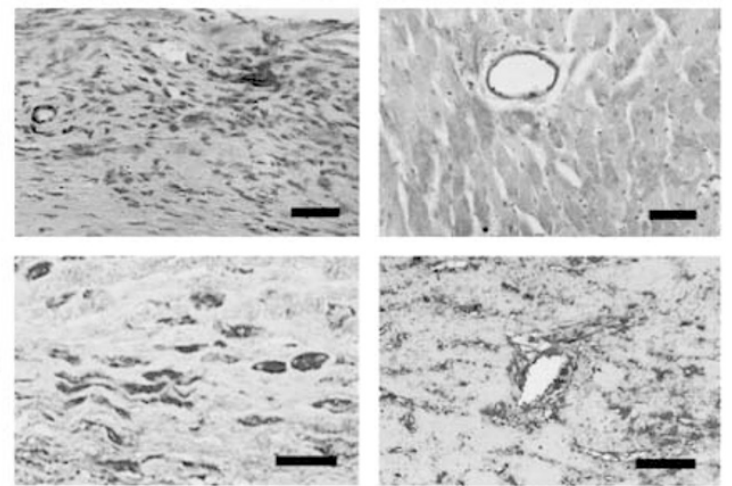

Figure 6 Expression of cardiac fibrosis-related proteins. (a) Western blot showing myocardial expression of MMP-2 and -9, TIMP-1 and -2, AT1 and TGF- $\beta 1$. (b) Their quantification by densitometry. (c) Myocardial TNF- $\alpha$ content determined by ELISA. ${ }^{*} P<0.05$. (d) Immunohistochemistry for MMP-2 and -9, AT1, and TGF- $\beta 1$ in infarcted (left panels) and noninfarcted (right panels) areas of hearts with 16-week-old MI. Immunohistochemical preparations for MMP-2 and MMP-9 shown here were obtained from the G-CSF-treated hearts, and those for AT1 and TGF- $\beta 1$ were from the untreated hearts. Bars, $20 \mu \mathrm{m}$.

among surviving cardiomyocytes and reduced myocardial fibrosis. Treatment with G-CSF induced activation of Stat 3 and Akt followed by upregulation of GATA-4, sarcomeric proteins and gelatinases (MMP-2 and -9), and downregulation of myocardial TNF- $\alpha$, AT1 and TGF- $\beta$, which likely provides a molecular basis for the beneficial effects of G-CSF on the failing post-MI heart. On the other hand, neither myocardial regeneration from bone marrow-derived cells nor an antiapoptotic effect among cardiomyocytes appeared to contribute to the beneficial effects of G-CSF.

We found the cardiomyocyte hypertrophy and attenuated degeneration induced by G-CSF particularly noteworthy, as they are likely the critical mechanisms contributing to the beneficial effects of this cytokine on cardiac function.
Hypertrophic growth of the myocardium is thought to preserve pump function, although prolongation of the hypertrophic state is a leading predictor of arrhythmias, sudden death and heart failure. ${ }^{31,32}$ However, not all forms of cardiac hypertrophy are necessarily pathological, as athletic conditioning can stimulate heart growth without deleterious consequence. ${ }^{33}$ Activation of downstream signaling by growth hormone, insulin-like growth factor and PI3K/Akt reportedly mediates a 'physiological' type of cardiac hypertrophy. ${ }^{34,35}$ The observed G-CSF-induced hypertrophy cannot be simply explained as a compensatory response because the hypertrophic reaction was more pronounced in G-CSF-treated hearts, which showed less severe heart failure than was seen in the untreated hearts. 

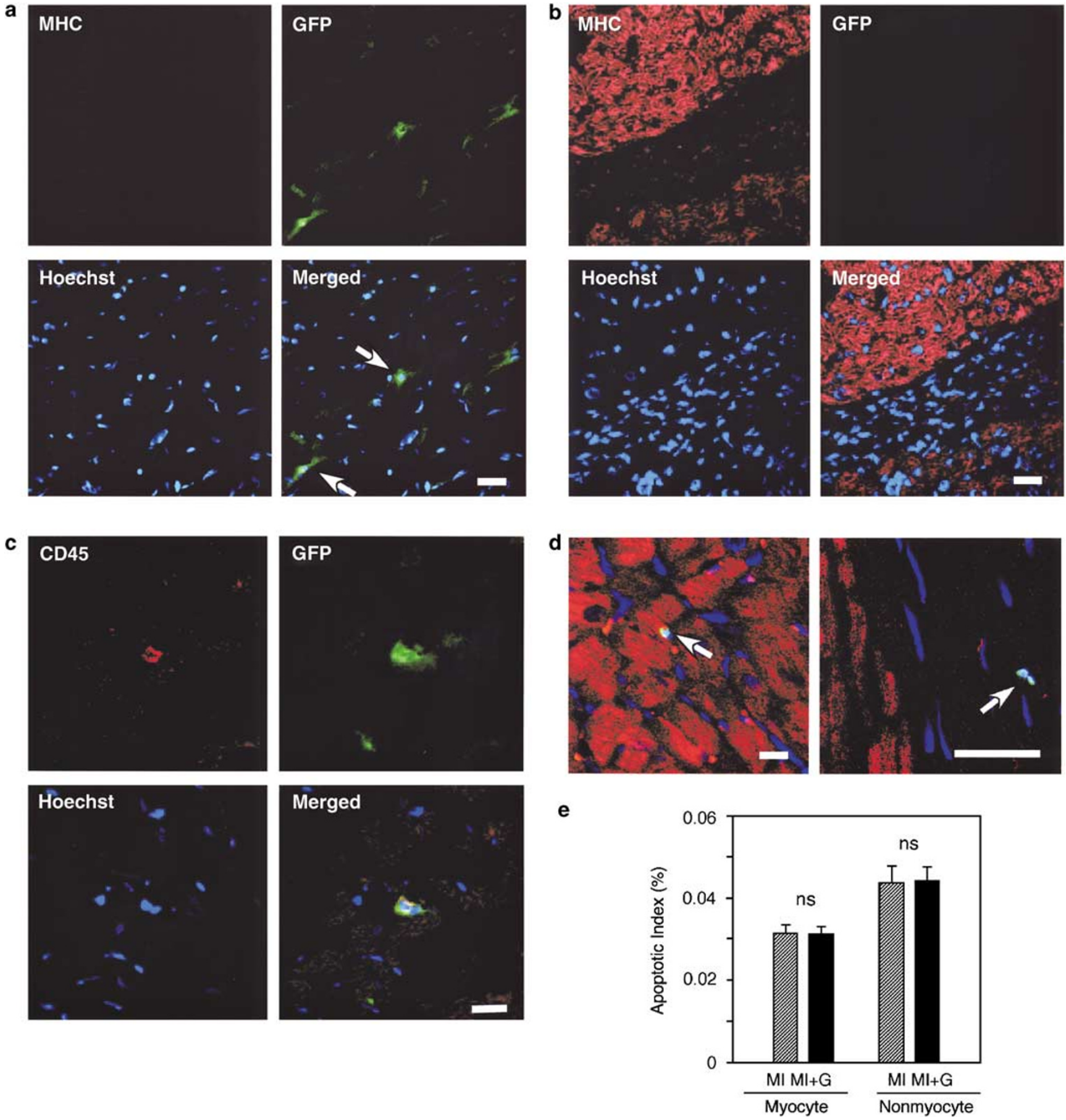

Figure 7 Confocal micrographs of G-CSF-treated hearts with 16-week-old MIs. (a and b) Infarcted (a) and noninfarcted area bordering infarcted area (b) double stained for MHC (red) and GFP (green). Nuclei are stained with Hoechst (blue). (a) GFP-positive, bone marrow cell-derived cells with round or fibroblast-like shapes in the infarct area (arrows). (b) Absence of GFP-positive cells (green) in the noninfarcted area. (c) Cells positive for both GFP (green) and CD45 (red) were observed, though only rarely. (d) TUNEL-positive cardiomyocytes (left panel) and noncardiomyocytes (right panel) in the infarcted area (arrows): TUNEL (green); MHC (red); nuclei (blue). (e) Incidence of TUNEL-positive cells among cardiomyocytes and noncardiomyocytes. Bar in all panels, $20 \mu \mathrm{m}$.

We found that the level of G-CSFR expression was markedly higher in untreated failing hearts than in sham-operated hearts, but was still higher in the G-CSF-treated failing hearts. Unexpectedly, G-CSF also upregulated expression of G-CSFR in shamoperated hearts. Given that G-CSF is reportedly endogenously expressed in infarcted murine hearts, ${ }^{16,36}$ it is conceivable that the observed upregulation of G-CSFR expression reflects a ligand-dependent autoinduction of G-CSFR gene expression similar to that reported for hepatocyte growth factor (HGF) and c-Met/HGF receptor. ${ }^{37}$ The 
G-CSFR signal activates a variety of intracellular signaling cascades, including the JAK/STAT, Ras/ Raf/MAPK, Src family kinase and PI3K/Akt pathways. ${ }^{6,24}$ In the present study, we detected increased activation of both Akt and Stat3-that is, increased levels of phospho-Akt and phospho-Stat3-in GCSF-treated hearts. In that regard, transgenic mice with cardiac-specific overexpression of active Akt not only exhibit hypertrophy but also enhanced LV function,,$^{34,35,38}$ as do transgenic mice with cardiacspecific overexpression of Stat $3 .^{39}$ We therefore suggest that these downstream signals of G-CSFR are associated with the cardiomyocyte hypertrophy observed in the G-CSF-treated hearts. In addition, the otherwise suppressed expression of myocardial GATA-4 was restored by G-CSF treatment, and expression the sarcomeric proteins MHC, troponin I and desmin, the first two of which are transcriptionally regulated by GATA $-4,{ }^{25,26}$ were upregulated in G-CSF-treated hearts.

A second important finding of the present study was that cardiac fibrosis is significantly diminished in G-CSF-treated hearts. This may have significantly contributed to the G-CSF-induced improvement in cardiac function, as myocardial fibrosis is one of the most characteristic structural changes in infarcted hearts, contributing to both systolic and diastolic dysfunction. $^{40}$ G-CSF was previously shown to induce MMP-2 and $-9,{ }^{27}$ and we confirmed their upregulation in G-CSF-treated hearts. In fact, members of the MMP family of extracellular matrix proteases are generally upregulated in failing hearts, and often their inhibition has a beneficial effect on cardiac remodeling and function. ${ }^{41}$ This is because increases in MMPs likely exacerbate heart failure by catalyzing collagen degradation as well as cleavage of pro-TNF- $\alpha$ to yield mature TNF- $\alpha,{ }^{42}$ although no change in collagen content was seen in those studies. It is well known, however, that fibrosis, particularly interstitial fibrosis, often becomes excessive in failing hearts, accelerating cardiac remodeling and dysfunction, as was the case in the present model. Under those circumstances, an increase in MMP family proteins might exert a protective effect by catalyzing the degradation of the excessive collagen. Consistent with that idea, several studies have shown that inhibition of MMP causes cardiac failure; ${ }^{43}$ that targeted deletion of MMP-9 attenuates LV remodeling and collagen accumulation caused by overexpression of MMP-2 and MMP-13;44 and that an increase in MMP-1 induced by HGF has a beneficial effect on post-MI heart failure via its anti-fibrotic action. ${ }^{45}$ It is therefore conceivable that upregulation of MMP-2 and -9 expression mediated by G-CSFR signaling might mitigate cardiac dysfunction by reducing the excessive fibrosis in hearts with old MIs.

Recently, Harada et $a l^{16}$ elegantly elucidated a critical role of Jak/Stat pathway activation, downstream of G-CSFR, for beneficial effects of G-CSF on post-MI process in mice. We confirmed activation of myocardial Stat3 by G-CSF in the present study. However, very different experimental models were used in Harada's study and ours; they used G-CSF during the acute stage of MI and evaluated the effect at subacute to early chronic stage (2 weeks post-MI), while we started G-CSF treatment on established heart failure with healed MI (8 and 12 weeks postMI) and evaluated it 4 more weeks later. More importantly, the phenotypes induced by G-CSF were very different. One of the main findings of the Harada et al's study was antiapoptosis in cardiomyocytes and vessels during the acute and subacute stages of MI, but cardiomyocyte hypertrophy and anti-fibrosis during the chronic stage were ours.

Orlic et $a l^{8}$ were the first to report that treatment with hematopoietic cytokines increased the mobilization of bone marrow-derived stem cells to injured myocardium and promoted myocardial regeneration. They found that preinfarction treatment with stem cell factor and G-CSF resulted in myocardial regeneration characterized by dividing cardiomyocytes and formation of vascular structures during the chronic stage of MI, which significantly improved cardiac function and decreased mortality. It is now widely accepted that administration of GCSF during the acute stage of MI, even if started postinfarction, can improve cardiac function in animals after acute MI. ${ }^{8,13-16}$ Using GFP chimeric mice in the present study (Protocol-3 in the Materials and methods section), we found that the bone marrow-derived cells present in hearts with old MIs consisted only of a few fibroblast-like cells and leukocytes, but not cardiomyocytes or vascular cells, and their presence was not influenced by treatment with G-CSF. This negative finding might reflect the absence of active inflammatory foci and, thus, the absence of an abundance of the chemokines and chemokine receptors responsible for the trafficking and homing of inflammatory cells in chronic stage post-MI hearts. ${ }^{46}$ Still, we cannot rule out its possibility that some bone marrow-derived cardiomyocytes were present because we did not examine the entire heart. Having said that, however, the possibility of transdifferentiation of hematopoietic stem cells into cardiomyocytes, with or without the help of G-CSF, has recently been challenged, ${ }^{10-12}$ and our negative finding further suggests that the contribution made by myocardial regeneration to the beneficial effects of G-CSF in old MI is likely small, at best.

Akt reportedly plays a critical role in cell survival and angiogenesis. ${ }^{47}$ However, we very rarely detected apoptotic cardiomyocytes in the present experimental setting, even in the untreated hearts. Apoptosis among noncardiomyocytes was also rare, and the population of vessels in the infarcted area was similar in treated and untreated hearts. The lack of Evans blue-positive cardiomyocytes-that is, cardiomyocytes with leaky plasma membranesfurther suggests that cardiomyocyte death is not a 
significant factor in the present model. In addition, no cardiomyocytes immunohistochemically positive for Ki-67 were observed, making cardiomyocyte proliferation unlikely. Despite a significant activation of Akt, we could not note a greater population of Flk-1-positive vessels in the G-CSF-treated hearts of the present model, and can offer no explanation for this negative finding.

G-CSF has already been confirmed to be safe and is widely used in patients with granulocytopenia, as well as in healthy individuals donating bone marrow for transplantation. The daily dose of GCSF used in the present study $(10 \mu \mathrm{g} / \mathrm{kg} /$ day) was well within the clinical dosage range used in humans. ${ }^{48}$ Importantly, we found that the effect of G-CSF on cardiac function persisted long (at least 2 weeks) after administration ceased. (Protocol-2 in the Materials and methods section). Although one recent report suggests the possibly of a higher incidence of coronary restenosis among patients treated with G-CSF, ${ }^{49}$ this adverse effect may be avoided by reducing the dosage. ${ }^{50}$ It will be necessary to confirm the safety of its long-term administration and to construct appropriate administration protocols for clinical application carefully, but our findings suggest G-CSF administration may represent a new therapeutic strategy for treating patients with chronic heart failure.

\section{Acknowledgements}

We thank Akiko Tsujimoto, Hatsue Ohshika and the staff of Kyoto Women's University (Michiyo Takagaki, Etsuko Takegawa, Yukiko Masuda) for technical assistance. This work was supported in part by grants-in-aid for scientific research 15209027, 15590732, 14570700 and 13470143 from the Ministry of Education, Science and Culture of Japan and by a grant from the Nagono Medical Foundation.

\section{References}

1 Hunter JJ, Chien KR. Signaling pathways for cardiac hypertrophy and failure. N Engl J Med 1999;341: 1276-1283.

2 Pfeffer MA, Braunwald E. Ventricular remodeling after myocardial infarction: experimental observations and clinical implications. Circulation 1990;81:1161-1172.

3 Reimer KA, Vander Heide RS, Richard VJ. Reperfusion in acute myocardial infarction: effect of timing and modulating factors in experimental models. Am J Cardiol 1993;72:13G-21G.

4 Hosenpud JD, Bennett LE, Keck BM, et al. The registry of the international society for heart and lung transplantation: seventeenth official report-2000. J Heart Lung Transplant 2000;19:909-931.

5 Metcalf D. Control of granulocytes and macrophages: molecular, cellular, and clinical aspects. Science 1991; 254:529-533.
6 Avalos BR. Molecular analysis of the granulocyte colony-stimulating factor receptor. Blood 1996;88: 761-777.

7 Link DC. Mechanisms of granulocyte colony-stimulating factor-induced hematopoietic progenitor-cell mobilization. Semin Hematol 2000;37(Suppl 2):25-32.

8 Orlic D, Kajstura J, Chimenti S, et al. Mobilized bone marrow cells repair the infarcted heart, improving function and survival. Proc Natl Acad Sci USA 2001;98:10344-10349.

9 Makino S, Fukuda K, Miyoshi S, et al. Cardiomyocytes can be generated from marrow stromal cells in vitro. J Clin Invest 1999;103:697-705.

10 Murry CE, Soonpaa MH, Reinecke H, et al. Haematopoietic stem cells do not transdifferentiate into cardiac myocytes in myocardial infarcts. Nature 2004;428: 664-668.

11 Balsam LB, Wagers AJ, Christensen JL, et al. Haematopoietic stem cells adopt mature haematopoietic fates in ischaemic myocardium. Nature 2004;428:668-673.

12 Norol F, Merlet P, Isnard R, et al. Influence of mobilized stem cells on myocardial infarct repair in a nonhuman primate model. Blood 2003;102: 4361-4368.

13 Kocher AA, Schuster MD, Szabolcs MJ, et al. Neovascularization of ischemic myocardium by human bonemarrow-derived angioblasts prevents cardiomyocyte apoptosis, reduces remodeling and improves cardiac function. Nat Med 2001;7:430-436.

14 Ohtsuka M, Takano H, Zou Y, et al. Cytokine therapy prevents left ventricular remodeling and dysfunction after myocardial infarction through neovascularization. FASEB J 2004;18:851-853.

15 Minatoguchi S, Takemura G, Chen XH, et al. Acceleration of the healing process and myocardial regeneration may be important as a mechanism of improvement of cardiac function and remodeling by postinfarction granulocyte colony-stimulating factor treatment. Circulation 2004;109:2572-2780.

16 Harada M, Qin Y, Takano H, et al. G-CSF prevents cardiac remodeling after myocardial infarction by activating the Jak-Stat pathway in cardiomyocytes. Nat Med 2005;11:305-311.

17 Elsässer A, Suzuki K, Schaper J. Unresolved issues regarding the role of apoptosis in the pathogenesis of ischemic injury and heart failure. J Mol Cell Cardiol 2000;32:711-724.

18 Kang PM, Izumo S. Apoptosis and heart failure: a critical review of the literature. Circ Res 2000;86: 1107-1113.

19 Takemura G, Fujiwara H. Role of apoptosis in remodeling after myocardial infarction. Pharmacol Ther 2004;104:1-16.

$20 \mathrm{Li} \mathrm{Y,} \mathrm{Takemura} \mathrm{G,} \mathrm{Kosai} \mathrm{K,} \mathrm{et} \mathrm{al.} \mathrm{Postinfarction}$ treatment with an adenoviral vector expressing hepatocyte growth factor relieves chronic left ventricular remodeling and dysfunction in mice. Circulation 2003;107:2499-2506.

21 Kawada T, Nakazawa M, Nakauchi S, et al. Rescue of hereditary form of dilated cardiomyopathy by rAAVmediated somatic gene therapy: amelioration of morphological findings, sarcolemmal permeability, cardiac performances, and the prognosis of TO-2 hamsters. Proc Natl Acad Sci USA 2002;99:901-906.

22 Okabe M, Ikawa M, Kominami K, et al. 'Green mice' as a source of ubiquitous green cells. FEBS Lett 1997; 407:313-319. 
23 Kushida T, Inaba M, Hisha H, et al. Intra-bone marrow injection of allogeneic bone marrow cells: a powerful new strategy for treatment of intractable autoimmune diseases in MRL/lpr mice. Blood 2001;97:3292-3299.

24 Dong F, Larner AC. Activation of Akt kinase by granulocyte colony-stimulating factor (G-CSF): evidence for the role of a tyrosine kinase activity distinct from the janus kinases. Blood 2000;95:1656-1662.

25 Molkentin JD, Kalvakolanu DV, Markham BE. Transcription factor GATA-4 regulates cardiac musclespecific expression of the alpha-myosin heavy-chain gene. Mol Cell Biol 1994;14:4947-4957.

26 Murphy AM, Thompson WR, Peng LF, et al. Regulation of the rat cardiac troponin I gene by the transcription factor GATA-4. Biochem J 1997;322:393-401.

27 Carstanjen D, Ulbricht N, Iacone A, et al. Matrix metalloproteinase-9 (gelatinase B) is elevated during mobilization of peripheral blood progenitor cells by G-CSF. Transfusion 2002;42:588-596.

28 Mann DL. Inflammatory mediators and the failing heart: past, present, and the foreseeable future. Circ Res 2002;91:988-998.

29 Peng J, Gurantz D, Tran V, et al. Tumor necrosis factoralpha-induced AT1 receptor upregulation enhances angiotensin II-mediated cardiac fibroblast responses that favor fibrosis. Circ Res 2002;91:1119-1126.

$30 \mathrm{Yu}$ CM, Tipoe GL, Wing-Hon Lai K, et al. Effects of combination of angiotensin-converting enzyme inhibitor and angiotensin receptor antagonist on inflammatory cellular infiltration and myocardial interstitial fibrosis after acute myocardial infarction. J Am Coll Cardiol 2001;38:1207-1215.

31 Ho KK, Pinsky JL, Kannel WB, et al. The epidemiology of heart failure: the Framingham Study. J Am Coll Cardiol 1993;22:6A-13A.

32 Lloyd-Jones DM. The risk of congestive heart failure: sobering lessons from the Framingham Heart Study. Curr Cardiol Rep 2001;3:184-190.

33 Oakley D. General cardiology: the athlete's heart. Heart 2001;86:722-726.

34 McMullen JR, Shioi T, Zhang L, et al. Phosphoinositide 3-kinase(p110alpha) plays a critical role for the induction of physiological, but not pathological, cardiac hypertrophy. Proc Natl Acad Sci USA 2003; 100:12355-12360.

35 Tanaka N, Ryoke T, Hongo M, et al. Effects of growth hormone and IGF-I on cardiac hypertrophy and gene expression in mice. Am J Physiol 1998;275: H393-H399.

36 Woldbaek PR, Hoen IB, Christensen G, et al. Gene expression of colony-stimulating factors and stem cell factor after myocardial infarction in the mouse. Acta Physiol Scand 2002;175:173-181.

37 Ueda H, Nakamura T, Matsumoto K, et al. A potential cardioprotective role of hepatocyte growth factor in myocardial infarction in rats. Cardiovasc Res 2001; 51:41-50.
38 Kim YK, Kim SJ, Yatani A, et al. Mechanism of enhanced cardiac function in mice with hypertrophy induced by overexpressed Akt. J Biol Chem 2003; 278:47622-47628.

39 Kunisada K, Negoro S, Tone E, et al. Signal transducer and activator of transcription 3 in the heart transduces not only a hypertrophic signal but a protective signal against doxorubicin-induced cardiomyopathy. Proc Natl Acad Sci USA 2000;97:315-319.

40 Jalil JE, Doering CW, Janicki JS, et al. Fibrillar collagen and myocardial stiffness in the intact hypertrophied rat left ventricle. Circ Res 1989;64:1041-1050.

41 Spinale FG. Matrix metalloproteinases: regulation and dysregulation in the failing heart. Circ Res 2002;90: 520-530.

42 Gearing AJ, Beckett P, Christodoulou M, et al. Processing of tumour necrosis factor-alpha precursor by metalloproteinases. Nature 1994;370:555-557.

43 Heymans S, Luttun A, Nuyens D, et al. Inhibition of plasminogen activators or matrix metalloproteinases prevents cardiac rupture but impairs therapeutic angiogenesis and causes cardiac failure. Nat Med 1999;5:1135-1142.

44 Ducharme A, Frantz S, Aikawa M, et al. Targeted deletion of matrix metalloproteinase-9 attenuates left ventricular enlargement and collagne accumulation after experimental myocardial infarction. J Clin Invest 2000;106:55-62.

45 Taniyama Y, Morishita R, Nakagami H, et al. Potential contribution of a novel antifibrotic factor, hepatocyte growth factor, to prevention of myocardial fibrosis by angiotensin II blockade in cardiomyopathic hamsters. Circulation 2000;102:246-252.

46 Rosen SD. Ligands for L-selectin: homing, inflammation, and beyond. Annu Rev Immunol 2004;22: 129-156.

47 Shiojima I, Walsh K. Role of Akt signaling in vascular homeostasis and angiogenesis. Circ Res 2002;90: 1243-1250.

48 Kroger N, Renges H, Kruger W, et al. A randomized comparison of once vs twice daily recombinant human granulocyte colony-stimulating factor (filgrastim) for stem cell mobilization in healthy donors for allogeneic transplantation. Br J Haematol 2000;111:761-765.

49 Kang HJ, Kim HS, Zhang SY, et al. Effects of intracoronary infusion of peripheral blood stem-cells mobilised with granulocyte-colony stimulating factor on left ventricular systolic function and restenosis after coronary stenting in myocardial infarction: the MAGIC cell randomised clinical trial. Lancet 2004; 363:751-756.

50 Valgimigli M, Rigolin GM, Cittanti C, et al. Use of granulocyte-colony stimulating factor during acute myocardial infarction to enhance bone marrow stem cell mobilization in humans: clinical and angiographic safety profile. Eur Heart J 2005;26: 1838-1845. 